\title{
The effect of prosody teaching on developing word recognition skills for interpreter trainees:
}

\section{An experimental study}

Mahmood Yenkimaleki, Vincent J. van Heuven

Leiden University Centre for Linguistics

m.yenkimaleki@hum.leidenuniv.nl

Department of Applied Linguistics Pannon Egyetem, Egyetem Utca

v.j.j.p.van.heuven@hum.leidenuniv.nl

\begin{abstract}
The present study investigates the effect of the explicit teaching of prosodic features on developing word recognition skills with interpreter trainees. Two groups of student interpreters were composed. All were native speakers of Farsi who studied English translation and interpreting at the BA level at the State University of Arak, Iran. Participants were categorized into two groups at random, but with equal division between genders ( 9 female and 9 male students in each group). No significant differences in English language skills (TOEFL scores) could be established between the groups. Participants took a pretest of word recognition skill before starting the program. The control group received exercises in listening comprehension, while the experimental group spent part of the time on theoretical explanation and practical exercises developing conscious knowledge of prosodic features of English, such as word stress. The total instruction time was the same for both groups, i.e. 8 hours. Students then took a posttest of word recognition skills. The results show that prosodic feature awareness training did yield a statistically significant improvement of word recognition skills. The result has pedagogical implications for researchers in the field of second language teaching, instructors, curriculum designers, conductors of interpreting programs for training future interpreters, material producers and all who are involved in language study and pedagogy.
\end{abstract}

\section{Indexing terms/Keywords}

word recognition, prosody, word stress, interpreting, English as a Foreign Language.

\section{Academic Discipline And Sub-Disciplines}

Humanities, linguistics, applied linguistics, interpreting and translation studies, psycholinguistics

\section{SUBJECT CLASSIFICATION}

Library of Congress Classification P306-310 (translating \& interpreting), BF309-499 (consciousness and cognition)

\section{TYPE (METHOD/APPROACH)}

\section{Experimental}

\section{INTRODUCTION}

Phonological awareness is the ability to consciously parse speech into its component sounds and to be able to manipulate these smaller units. This type of ability would influence the processing of spoken input. Different scholars emphasized the importance of phonological awareness in message perception during listening comprehension (e.g., Cheung 2007; Cheung, Chen, Lai, Wong, \& Hills 2001; Caravolas \& Buck 1993, reported in Li et al. 2012). Through phonological awareness listeners parse the stream of speech sounds into words and are then able to construct a sentence meaning from the meaning of the individual words (e.g., Salwen \& Stacks 1996, reported in Li et al. 2012). Li et al. (2012) stated that phonological awareness makes listeners sensitive to sound units in speech, which makes it easier to process speech and to retrieve the right words. As a result the listener will find it easier to recognize the words, process sentence meaning and comprehend the stream of speech.

Ahangari et al. (2015), in an experimental study in Iran, suggested that awareness training of pronunciation rules of English would improve the listening comprehension of learners of English as a Foreign Language (EFL). They randomly selected 42 participants out of 200 students. The participants were then randomly assigned to two groups (control and experimental) based on the time they preferred to spend on the training program. Twenty participants were assigned to the experimental group and 22 the control group. Both groups took a pretest exam and their listening comprehension skill was assessed. No significant difference was observed in the results. During 20 minutes in each treatment session, the instructor provided the experimental group with awareness training about the correct way of pronouncing the English words and then had them practice listening to authentic extracts. At the end of the 30 hours' training program, both groups took the same standard posttest of listening comprehension. The results indicated that awareness training had a positive effect on improving listening comprehension for the experimental group.

Poelmans (2003), among others, stated that in addition to the segmental categories, i.e. the vowels and consonants in the language, the stream of speech is characterized by prosodic features as well. These features are not related to specific, individual speech sounds but they subtend larger units of at least the size of a syllable. Prosodic features break up the 
continuous stream of speech into smaller chunks through pauses and boundary-marking pitch changes, and also highlight one syllable or word as the focus of the speaker's attention within the larger chunk (accentuation) (e.g. Nooteboom 1997). Generally, the segmental features serve to access words in the mental lexicon while the prosodic features guide the interpretation process (e.g. Cutler 2001).

Gilbert (2008) pointed out that prosodic phenomena are road signs that help the listener follow the intentions of the speaker in the stream of speech. These road signs impart emphasis to particular units (syllables, words) and signal the relationship between ideas so that listeners can easily identify these relationships and perceive the speaker's intention. Prosodic feature awareness training helps learners perceive words in context and recognize such prosodic road signs in spoken English; it also helps learners to clear up potential misunderstandings in the stream of a conversation. Gilbert (2008) suggested the principle of helping the listener to follow. She claimed that students who received training awareness about English prosodic patterns improved on perception of speech on TV, in movies, and in communication. Prosody training teaches students to perceive how to use rhythmic and melodic cues to organize information and guide the listener, and also how prosody, e.g. differences in word and sentence stress, changes the sound shapes of words.

Derwing and Rossiter (2003) also emphasized the importance of prosodic instruction. In an experimental study one group of students received instruction about segmentals while another group received instruction about prosodic features. They, then, concluded that by teaching prosodic features the pronunciation skill of non-native speakers improved significantly and they stated that teaching prosody to the EFL students should be a fundamental issue in the EFL curriculum.

Generally, in different studies, listening comprehension is looked upon as a skill used by listeners to perceive the global message of the utterances. There are not enough studies focusing on recognition of words, which is the first step towards listening comprehension. Word recognition is the process of breaking up the stream of sounds into linguistic units and consequently, retrieving the meaning of words from long-term memory while global listening comprehension is the process of integrating the meaning of words in the stream of speech into an interpretation of the overall utterance so that the message of the speaker can be reconstructed (Poelmans 2003). In this regard, Segalowitz and Segalowitz (1993) stated that automatization of the aural word recognition skill is fundamentally necessary in developing listening comprehension.

Therefore, word recognition is a fundamentally necessary subskill in enhancing listening comprehension as a skill needed in the interpreting profession. Since there are no systematic studies on the effect of prosody awareness training on the development of word recognition skills, we conducted an experimental study to investigate this issue systematically. Concretely we asked the following research question:

Does awareness training of prosodic features (stress at word level) lead to develop word recognition skill for student interpreter trainees?

Our hypothesis is that explicit teaching of prosody, especially focusing on differences in word stress between English and Farsi, should yield better word recognition skills and ultimately result in developing better listening comprehension in English.

The results of the study may be a reason for modifying the curriculum in interpreting studies and training qualified future interpreters.

\section{METHOD}

\subsection{Participants}

Thirty-six students of translation and interpreting between Farsi and English were chosen randomly from 68 junior students at Arak University, Iran. They were randomly divided into two classes of 18 students that each incorporated 9 male and 9 female students. The participants were native speakers of Farsi with an age range of 18-25 years. They participated in all sessions of the training.

\subsection{Procedure}

The participants were divided into control and experimental groups through the application of systematic random sampling. The control group received routine exercises (i.e. placebo), asking them to listen to authentic audio tracks in English and doing exercises based on questions about the contents of the audio tracks. The experimental group spent less time on these tasks and instead received prosodic feature awareness training for 15 minutes during each training session.

At the beginning of the program all the participants took a pretest of general English proficiency. The test battery was the standard Longman's TOEFL English proficiency test, with separate modules testing the learner's (i) Listening comprehension, (ii) Reading comprehension and (iii) Structure and writing skills. The participants took part in the program for eight sessions (one hour per session) in four weeks, i.e. 8 hours in all.

Altogether the control group listened to 320 minutes of authentic audio tracks and did the exercises based on them. Moreover, both the control group and the experimental group listened during 160 minutes to the Iranian instructor who explained how to do exercises in listening comprehension. The experimental group altogether listened for 200 minutes to authentic audio tracks and did the exercises based on them. Additionally, they listened for 60 minutes to the theoretical 
explanation of English prosody that was provided by the Iranian instructor and spent 60 minutes in all doing practical exercises in English prosody.

As part of the present study, the participants also participated in a pretest, and later in a posttest, designed to estimate their word recognition skill. These tests were designed by the first author and comprised 50 items each. To ensure equal difficulty of the pretest and the posttest, one hundred English words were chosen such that their recognition would be sensitive to differences in word stress (e.g. enter inter, desert $\sim$ dessert, with initial versus final stress, respectively, in each pair). A random selection of 50 words was then assigned to the pretest while the other 50 made up the posttest. The stimulus words were recorded as citation forms by a male native speaker of British English and presented to the participants over headphones in a language laboratory with a pause of 7 seconds between words (onset to onset). During the pause, listeners were required to write down the word they thought the speaker had produced.

The written responses given to the pretest and posttest were checked for correctness by the first author. A response was scored as either correct or wrong. Although spelling errors were accepted, the written response had to satisfy the condition that the identity of the word could be established. No attempt was made to mark responses as partially correct when there was an incomplete overlap between the intended and responded word. As a consequence the subject-individual scores on the word-recognition tests could range between 0 and 50 correct responses in integer steps.

\subsection{Data analysis}

In order to see whether the participants were homogeneously distributed over the two groups a Two-Sample KolmogorovSmirnov test was run. Linear Regression was conducted in order to determine the extent to which components of the TOEFL language proficiency pretests predict a student's performance in the posttest. To see whether the difference between the mean scores of the experimental and control groups is statistically meaningful, t-tests were performed. The correlation between pretest scores and posttest scores was established by the Pearson correlation coefficient.

\section{RESULTS: EFFECT OF PROSODY TEACHING}

Table 1 summarizes the raw component scores of the proficiency test of the control group (left-hand part of table) and of the experimental group (right-hand part).

Table 1: Raw component and overall scores on TOEFL proficiency test obtained by control (left-hand part) and experimental groups (right-hand part). Within each group participants are listed in descending order of the overall TOEFL score.

\begin{tabular}{|c|c|c|c|c|c|c|c|c|c|c|c|c|c|}
\hline & & & \multicolumn{3}{|c|}{ Control Group } & 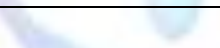 & \multicolumn{7}{|c|}{ Experimental group } \\
\hline Nr. & ID & Gend. & $\begin{array}{l}\text { List. } \\
\text { Comp }\end{array}$ & $\begin{array}{c}\text { Struct. \& } \\
\text { Writing }\end{array}$ & $\begin{array}{l}\text { Read. } \\
\text { Comp }\end{array}$ & $\begin{array}{l}\text { Overall } \\
\text { TOEFL }\end{array}$ & Nr. & ID & Gend. & $\begin{array}{l}\text { List. } \\
\text { Comp }\end{array}$ & $\begin{array}{c}\text { Struct. \& } \\
\text { Writing }\end{array}$ & \begin{tabular}{|c|} 
Reading \\
Comp
\end{tabular} & $\begin{array}{l}\text { Overall } \\
\text { TOEFL }\end{array}$ \\
\hline 1. & $\operatorname{ReA}$ & M & 60 & 58 & 61 & 596.6 & 1. & $\mathrm{JaN}$ & $\mathrm{M}$ & 59 & 63 & 61 & 610.0 \\
\hline 2. & SaS & $F$ & 59 & 57 & 59 & 583.3 & 2. & FaN & $F$ & 59 & 56 & 58 & 576.6 \\
\hline 3. & $\mathrm{HaD}$ & M & 57 & 56 & 57 & 566.6 & 3. & AmD & $\mathrm{M}$ & 58 & 57 & 56 & 570.0 \\
\hline 4. & MaM & $F$ & 57 & 55 & 56 & 560.0 & 4. & $\mathrm{FaB}$ & $F$ & 57 & 56 & 55 & 560.0 \\
\hline 5. & SiK & M & 55 & 53 & 56 & 546.6 & 5. & AlK & $\mathrm{M}$ & 56 & 55 & 55 & 553.3 \\
\hline 6. & LeD & $F$ & 55 & 52 & 55 & 540.0 & 6. & YaM & $F$ & 54 & 54 & 55 & 543.3 \\
\hline 7. & $\mathrm{PaH}$ & $\mathrm{M}$ & 55 & 53 & 53 & 536.6 & 7. & SaR & $M$ & 53 & 54 & 54 & 536.6 \\
\hline 8. & GoR & $F$ & 54 & 53 & 52 & 530.0 & 8. & RaT & $F$ & 52 & 54 & 53 & 530.0 \\
\hline 9. & $\mathrm{JaB}$ & $M$ & 53 & 54 & 51 & 526.6 & 9. & $\mathrm{HaS}$ & $M$ & 52 & 52 & 53 & 523.3 \\
\hline 10. & TiR & $F$ & 52 & 54 & 49 & 516.6 & 10. & FeN & $F$ & 51 & 53 & 52 & 520.0 \\
\hline 11. & JaM & $\mathrm{M}$ & 51 & 52 & 49 & 506.6 & 11. & MeR & $M$ & 50 & 52 & 52 & 513.3 \\
\hline 12. & AtR & $F$ & 50 & 51 & 49 & 500.0 & 12. & HaR & $F$ & 51 & 51 & 51 & 510.0 \\
\hline 13. & AkJ & $M$ & 50 & 50 & 49 & 496.6 & 13. & $\mathrm{AbS}$ & $M$ & 49 & 50 & 50 & 496.6 \\
\hline 14. & $\mathrm{PaF}$ & $F$ & 49 & 50 & 49 & 493.3 & 14. & $\mathrm{NaN}$ & $F$ & 48 & 50 & 50 & 493.3 \\
\hline 15. & HoT & $M$ & 48 & 50 & 49 & 490.0 & 15. & BeR & $M$ & 47 & 49 & 49 & 483.3 \\
\hline 16. & ZaK & $F$ & 48 & 49 & 49 & 486.6 & 16. & $\mathrm{PaN}$ & $F$ & 46 & 48 & 48 & 473.3 \\
\hline 17. & $\mathrm{HaK}$ & $M$ & 47 & 49 & 48 & 480.0 & 17. & $\mathrm{AmM}$ & $M$ & 45 & 48 & 47 & 466.6 \\
\hline
\end{tabular}




\begin{tabular}{|l|l|l|l|l|l|l|l|l|l|l|l|c|}
\hline 18. PaK & $\mathrm{F}$ & 46 & 48 & 47 & 470.0 & 18. & MoM & $\mathrm{F}$ & 44 & 48 & 46 & 460.0 \\
\hline Mean & & 52.6 & 52.4 & 52.1 & 523.7 & Mean & & 51.7 & 52.8 & 52.5 & 523.3 \\
\hline SD & & 4.2 & 2.8 & 4.2 & 36.7 & SD & & 4.7 & 3.8 & 3.8 & 41 \\
\hline
\end{tabular}

One-sample Kolmogorov-Smirnov (KS) tests were run to ascertain that the overall TOEFL proficiency scores were distributed both normally and uniformly. The results show that the distribution of the scores were both uniform, $z=.674$ ( $p$ $=.796)$ and normal, $z=.704(p=.705)$. Moreover, a two-samples KS test showed that the shape of the distribution of the TOEFL scores did not significantly differ between the experimental and control group, $z=.707(p=.699)$. It was decided that standard parametric statistics could be safely used to analyze the data.

A t-test for unrelated samples then shows that none of the small differences on the pretest and its components between the experimental and control group are significant, $t(34)=.482(p=.633)$ for Listening comprehension, $t(34)=.788(p=$ .437) for Structure and written expression, $t(34)=1.421(p=.168)$ for Reading comprehension and $t(34)=-.703(p=$ .487) for the overall TOEFL proficiency score.

Before starting the awareness training program, a word recognition pretest was administered. This test was designed by the instructor. It comprised 50 items (see above). In order to make the pretest and the posttest of word recognition skill have the same level of difficulty, one hundred English words were chosen such that stress would play a potentially important role in differentiation of meaning in these words. A random selection of 50 words was used in the pretest, the other 50 in the posttest. After having awareness training program for eight sessions, the posttest of word recognition skill was run to investigate the effect of training program on experimental and control groups in developing word recognition skill. The results of pretest and posttest of word recognition skill are presented in Table 2.

Table 2: Pretest scores and posttest word recognition scores for control (left-hand part) and experimental (righthand part) groups. The last two rows contain the mean and standard deviation of the scores. Participants are ordered as in Table 1.

\begin{tabular}{|c|c|c|c|c|c|c|c|c|c|}
\hline & & Contro & Group & & & & rimental & oup & \\
\hline Nr. & ID & Gender & Pretest & Posttest & Nr. & ID & Gender & Pretest & Posttest \\
\hline 1. & $\operatorname{ReA}$ & Male & 40 & 42 & 1. & JaN & Male & 39 & 43 \\
\hline 2. & SaS & Female & 37 & 38 & 2. & $\mathrm{FaN}$ & Female & 38 & 44 \\
\hline 3. & $\mathrm{HaD}$ & Male & 36 & 37 & 3. & $A m D$ & Male & 39 & 42 \\
\hline 4. & MaM & Female & 35 & 34 & 4. & $\mathrm{FaB}$ & Female & 37 & 41 \\
\hline 5. & $\mathrm{SiK}$ & Male & 33 & 32 & 5. & AlK & Male & 35 & 40 \\
\hline 6. & LeD & Female & 33 & 31 & 6. & YaM & Female & 33 & 33 \\
\hline 7. & $\mathrm{PaH}$ & Male & 33 & 34 & 7. & $\mathrm{SaR}$ & Male & 34 & 38 \\
\hline 8. & GoR & Female & 32 & 34 & 8. & RaT & Female & 32 & 31 \\
\hline 9. & $\mathrm{JaB}$ & Male & 31 & 32 & 9. & $\mathrm{HaS}$ & Male & 32 & 37 \\
\hline 10. & TiR & Female & 31 & 32 & 10. & $\mathrm{FeN}$ & Female & 31 & 36 \\
\hline 11. & JaM & Male & 32 & 32 & 11. & MeR & Male & 32 & 37 \\
\hline 12. & AtR & Female & 33 & 30 & 12. & $\mathrm{HaR}$ & Female & 29 & 35 \\
\hline 13. & AkJ & Male & 30 & 31 & 13. & AbS & Male & 31 & 36 \\
\hline 14. & $\mathrm{PaF}$ & Female & 28 & 27 & 14. & $\mathrm{NaN}$ & Female & 28 & 27 \\
\hline 15. & HoT & Male & 26 & 25 & 15. & $\mathrm{BeR}$ & Male & 29 & 33 \\
\hline 16. & ZaK & Female & 25 & 26 & 16. & $\mathrm{PaN}$ & Female & 23 & 26 \\
\hline 17. & HaK & Male & 24 & 25 & 17. & AmM & Male & 22 & 25 \\
\hline 18. & PaK & Female & 22 & 23 & 18. & MoM & Female & 21 & 24 \\
\hline Mean & & & 31.17 & 31.39 & Mean & & & 31.39 & 34.89 \\
\hline SD & & & 4.7 & 4.9 & SD & & & 5.4 & 6.2 \\
\hline
\end{tabular}


An independent-samples t-test was chosen to compare the means of the two groups of participants. Before running the ttest, the test scores were submitted to the two-samples KS test to check the groups' final test results for normalcy, uniformity and homogeneity. It was concluded that the test scores of both groups are sufficiently homogeneous, so that $\mathrm{t}$ tests (and other parametric tests) can be safely used, $z=.707$ ( $p=.699$, two tailed).

The results bear out that there is no difference in word recognition between the experimental (31.4) and control (31.2) group in the pretest, $t(34)=.131(p=.897$, two tailed). An independent-samples t-test on the posttest scores for experimental and control groups shows that the 3.5-point advantage of the experimental group (34.9) over the control group (31.4) is highly significant, $t(34)=5.427(p=.001$, one-tailed). The effect of the intervention is conveniently expressed as the difference between the score on the posttest and on the pretest. A t-test for independent samples then shows that the improvement of word recognition in the experimental group is significantly better than in the control group, $t(34)=5.4(p<.001$, one-tailed). The conclusion follows that the experimental group gained significantly more by the intervention than the control group in terms of developing word recognition skill.

Figure 1, finally, plots the relationship between the overall TOEFL scores and posttest scores of the individual students, with separate symbols for participants in the experimental group and in the control group.

The overall correlation between the pre-test and post-test scores was $r=.884(N=36, p<.001)$. Moreover, as is shown in Figure 1, the overall TOEFL score obtained before the start of the intervention, though equally distributed for the experimental and control groups, range widely, i.e. between 450 and 650 on the TOEFL scale. The general result is that students with relatively poor (or good) TOEFL scores also obtain relatively poor (or good, respectively) word recognition scores, both in the pretest and in the posttest. So overall proficiency in English is the strongest determinant of the student's success on the word recognition tests. In addition to this, however, a much smaller but still highly significant gain is obtained by those students who took part in the prosodic feature awareness training program.

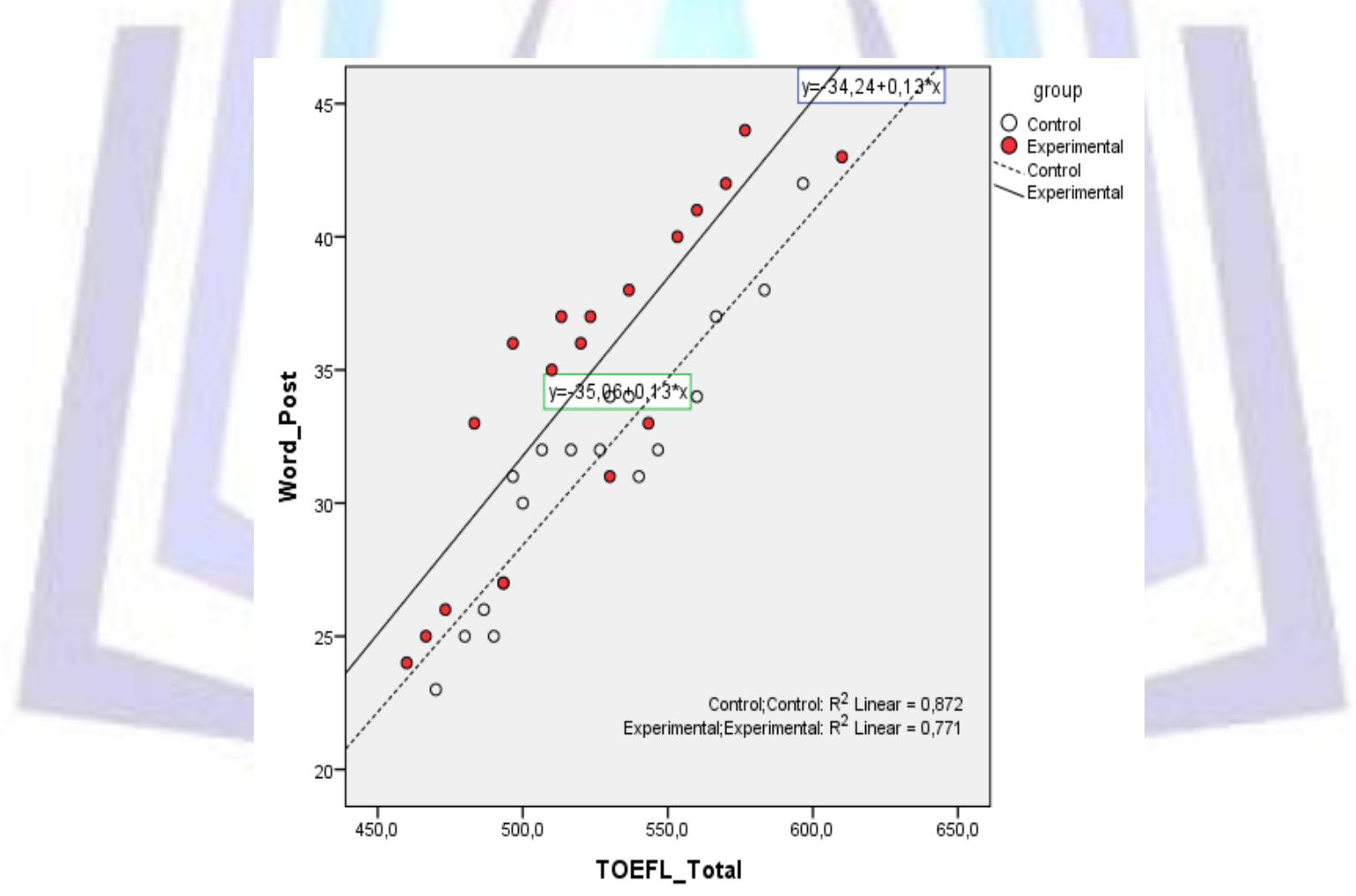

\footnotetext{
Figure 1: Post-test word-recognition score plotted against the overall TOEFL score for each of 36 participants. Members of the experimental group are indicated by closed markers, members of the control group by open markers.
}

\section{CONCLUSION}

In the present study the effect of explicit teaching of prosody on developing word recognition was investigated. The results of the study show that the explicit teaching of prosodic features contributes significantly to the interpreter trainees' developing word recognition skill. Statistical analysis of the data showed that conscious knowledge of prosodic features of stress at the word level has a positive effect on the participant's word recognition skill. This result is in line with Segalowitz \& Segalowitz (1993) who pointed out that developing word recognition is prerequisite stage in developing listening comprehension as a more general skill. Cutler (2001) also stated that conscious knowledge of prosodic features may help 
second-language learners retrieve words from their mental lexicon. Since in interpretation message perception plays an important role in the communication of message, explicit teaching of prosodic features for interpreter trainees can help them doing a better job. For this reason, the interpreter trainees need conscious knowledge of prosodic features of the language that they are interpreting into. If in training programs the issue of explicit teaching of prosody of the target language (and the prosodic differences between the source and the target languages) is practiced in class, then not only will the future interpreters acquire better word recognition skills in the target language but also develop better general listening comprehension skills - as other researchers (e.g. Segalowitz \& Segalowitz 1993) have pointed out.

The pedagogical implications of the present study would pertain to interpreting programs all over the world. Moreover, producers of textbooks and other teaching materials for use in the interpreting curriculum should include prosody awareness training, as should all the practitioners and researchers who are involved in the study/teaching of language in general.

\section{ACKNOWLEDGMENTS}

We are grateful to the University Assistant Fund and Leiden University Management Board that funded the first author's stay at the Leiden University Centre for Linguistics.

\section{REFERENCES}

1. Ahangari, S., Rahbar, S., \& Entezari Maleki, S. 2015. Pronunciation or listening enhancement: Two birds with one stone. International Journal of Language and Applied Linguistics, 1(2), 13-19.

2. Buck, G. 2001. Assessing listening. Cambridge: Cambridge University Press.

3. Cheung, H. 2007. The role of phonological awareness in mediating between reading and listening to speech. Language and Cognitive Processes, 22(1), 130-154.

4. Cheung, H., Chen, H.-C., Yip-Lai, C., Wong, O. C., \& Hills, M. 2001. The development of phonological awareness: Effects of spoken language experience and orthography. Cognition, 81(3), 227-241.

5. Cutler, A. 2001. Voornaam is not (really) a homophone: lexical prosody and lexical access in Dutch. Language and Speech, 44(2), 171-195.

6. Derwing, T. \& Rossiter, M. 2003. The effects of pronunciation instruction on the accuracy, fluency and complexity of L2 accented speech. Applied Language Learning, 13(1), 1-18.

7. Gilbert, J. B. 2008. Teaching pronunciation, using the prosody pyramid. Cambridge: Cambridge University Press.

8. Khaghaninejad, M. S. \& Maleki, A. 2015. The effect of explicit pronunciation instruction on listening comprehension: evidence from Iranian English learners. Theory and Practice in Language Studies, 5(6), 12491256.

9. Kraljic, T. \& Brennen. S. 2005. Prosodic disambiguation of syntactic structure: For the speaker or for the addressee?" Cognitive Psychology, 50(2), 194-231.

10. Lehiste, I. (1973). Phonetic disambiguation of syntactic ambiguity. Glossa, 7(2), 107-122.

11. Li, M., Cheng, L., \& Kirby, J. R. 2012. Phonological awareness and listening comprehension among Chinese English-immersion students. International Education, 41(2), 46-65.

12. Poelmans, P. 2003. Developing second-language listening comprehension: Effects of training lower-order skills versus higher-order strategy. Utrecht: LOT.

13. Price, P., Ostendorf, M., Shattuck-Huffnagel, S., \& Fong, C. 1991. The use of prosody in syntactic disambiguation." Journal of the Acoustical Society of America, 90(6), 2956-2970.

14. Schafer, A. 1997. Prosodic parsing: The role of prosody in sentence comprehension. Ph. D. thesis, University of Massachusetts at Amherst.

15. Schafer, A., Speer, S., \& Warren, P. 2005. Prosodic influences on the production and comprehension of syntactic ambiguity in a game-based conversation task. In J. Trueswell and M. Tanenhaus (Eds.), Approaches to studying world-situated language use: Bridging the action and product tradition. Cambridge, MA: MIT Press, 209-225.

16. Segalowitz, N. \& Segalowitz, S. 1993. Skilled performance, practice, and the differentiation of speed-up from automatization effects: Evidence from second language word recognition. Applied Linguistics, 14(3), 369-385.

17. Snedeker, J. \& Trueswell, J. 2003. Using prosody to avoid ambiguity: Effects of speaker awareness and referential context. Journal of Memory and Language, 48(1), 103-130.

18. Warren, P., Schafer, A, Speer, S., \& White, S. 2000. Prosodic resolution of prepositional phrase ambiguity in ambiguous and unambiguous situations. UCLA Working Papers in Phonetics, 99, 5-33. 
19. Xiaoyu, H. 2009. The relationship between Chinese EFL learners proficiency in suprasegmental features of pronunciation and their listening comprehension. CELEA Journal, 32(2), 31-39.

\section{Author' biography with Photo}

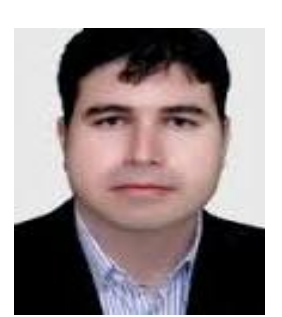

Mahmood Yenkimaleki is a guest scholar at Leiden University Centre for Linguistics and former head of translation and interpreting studies department at Tafresh University, Iran. His area of interest is interpreting studies and applied linguistics.

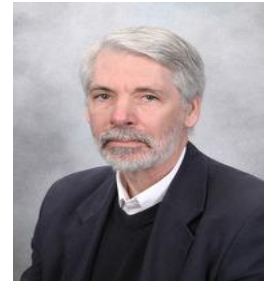

Vincent J. van Heuven (BA, MA, and PhD from Utrecht University) is an emeritus professor of Experimental Linguistics and Phonetics and former director of the Leiden University Centre for Linguistics. He is now a professor at the University of Pannonia in Veszprém, Hungary. He served on the editorial boards (and as associate editor) of Journal of Phonetics (Academic Press/Elsevier) and Phonetica (Karger) and was editor of the series Speech Research (Mouton de Gruyter). Over 40 doctoral dissertations were written under his (co-) supervision. He is a life member of the Royal Netherlands Academy of Arts and Sciences. 